\title{
The Current Role of Botox in a Pediatric Neurogenic Bladder Condition
}

\author{
Paweł Kroll ${ }^{1}$ \\ Published online: 9 May 2019 \\ (C) The Author(s) 2019
}

\begin{abstract}
Purpose of Review The neurogenic bladder is a medical term that describes a variety of bladder and sphincter dysfunctions. There are two major dangerous functional problems in a child with neurogenic bladder: high intravesical pressure in the storage phase and high pressure during urination. Two basic goals for urologic treatment in those children are protection of urinary tract from complications and improvement of continence in older children. This review focuses on the current role of botulinum toxin treatment in children with neurogenic bladder.

Recent Findings At the beginning, treatment in this group of children is conservative. Oral anticholinergic therapy is aimed at decreasing bladder pressures during the storage phase. Clean intermittent catheterization enables bladder emptying if voiding is insufficient. Nevertheless, in a number of children such an approach fails, in some patients, troublesome side effects occur. In cases when standard therapy provides no improvement or if complications develop on the proper conservative treatment, surgical procedures are suggested. Operations are aimed at the surgical enlargement of bladder capacity. There are some reports on the efficacy of cystoscopic detrusor botulinum toxin injections in the treatment of neurogenic bladder in children.

Summary Cystoscopic administration of botulinum toxin represents an alternative method of treatment to surgery for children with neurogenic bladder and could be considered an alternative to oral anticholinergic therapy.
\end{abstract}

Keywords Botulinum toxin $\cdot$ Neurogenic bladder $\cdot$ Child

\section{Introduction-Function of the Lower Urinary Tract}

The lower urinary tract, as one operating unit, consists of two anatomical parts, namely bladder and sphincters. The normal function of the lower urinary tract is to store urine for a reliable period of time and then evacuate it in a coordinated, controlled fashion. Proper age-related bladder capacity with continence

This article is part of the Topical Collection on Pediatric Bladder Dysfunction

Key Points Clean intermittent catheterization and oral anticholinergic pharmacotherapy of detrusor overactivity are the two most important principles in the treatment of a child with neurogenic bladder. There are some reports on the efficacy of cystoscopic detrusor botulinum toxin injections in the treatment of neurogenic bladder in children.

Paweł Kroll

pawelkroll.poczta@gmail.com

1 Pediatric Surgery and Urology Clinic, Neuro-urology Unit, Poznań University of Medical Sciences, Ul. Pamiątkowa 2/42, 61-512 Poznań, Poland in the storage phase and complete bladder emptying in the voiding phase are the most important factors. This coordinated activity of the lower urinary tract is regulated by many parts of the central and peripheral nervous systems. Neurogenic bladder (NB) is a medical term applied to a variety of bladder dysfunctions due to known neurological pathology [1-3].

In children younger than the age of 3 to 5 years, urination occurs involuntarily. At this period of life, voiding is controlled by the autonomic part of the central nervous system. In older children, it is regulated voluntarily. The evaluation of the bladder function in older children should begin with voiding diary (VD). VD or frequency/volume chart contains data on the hours and volumes of voided/catheterized urine as well as episodes of urine incontinence. The most important data from VD are the daytime number of micturitions, the average voided or catheterized volume of urine, and number of incontinence episodes per day. The data of maximal and functional bladder capacity from VD should be supported by urodynamic tests (UD) that are used to investigate both volume and specific for the volume pressures are recorded [4].

The most frequently used formula for the calculation of age-related bladder capacity for children is expected bladder 
capacity $(\mathrm{EBC})$ : volume $(\mathrm{ml})=30 \times[$ age $($ in years $)+1]$. Bladder capacity increases with the age from $30 \mathrm{~mL}$ in neonates to $350 \mathrm{~mL}$ in 12-year-old children $[5,6]$.

\section{Groups of Patients}

\section{Normal Bladder Function}

The child is urinating regularly in volumes of urine adequate to $\mathrm{EBC}$, without any complaints.

\section{Children Voiding Abnormally}

The child is urinating periodically but the volumes are not correct. There are three subgroups:

a) Increased voiding frequency with decreased volumes of urine. $\mathrm{Vol}<65 \% \mathrm{EBC}$ and $>8$ voids per day $(\mathrm{OAB}=$ overactive bladder syndrome with frequency and urgency symptoms).

b) Decreased voiding frequency with large volumes of urine. Vol $>150 \% \mathrm{EBC}$, and $<3$ voids per day (LBS = lazy bladder syndrome or voiding postponements).

c) Irregular voiding characterized by considerable differences in the voided volume in the consecutive urinations. In this group of children, significant residual urine is seen frequently (more than 10-20\% of voided volume).

Each of those conditions may be accompanied with additional symptoms, such as urgency, hesitancy, straining, or intermittency. In each group, urine incontinence or urinary tract infections may occur.

\section{Children Who Have Lost Control Over Their Bladder and Do Not Urinate at all}

The lack of control over urination is due to lack of sensation of bladder fullness and lack of urethral sensation or in whom that sensation is considerably decreased. This is characteristic of severe cases of the NB $[3,6]$.

\section{Neurogenic Bladder}

Congenital malformations, acquired diseases or injuries of any part of a nervous system, can influence the function of bladder and sphincters leading to problems with urination or even to complete loss of ability to urinate and urinary incontinence. The most common cause of NB in children is dysraphism malformations. Other causes of NB are cerebral palsy, sacral agenesis, tethered spinal cord, or malformations associated with imperforate anus, cloacal malformations, and spinal cord injuries. A child with NB should first undergo physical examination. Further tests are urinalysis and urine culture, biochemical tests, abdominal ultrasound, and UD investigations. Further examinations like cystography, renal scans, intravenous pyelography, and computed tomography are optional $[1-3,6]$.

\section{Urodynamic Investigation}

UD evaluations describe bladder function and dysfunction of the bladder and sphincters. Analyzing data from UD investigations, Madersbacher [7] described four groups of patients with NB:

a) Detrusor overactivity with sphincter overactivity

b) Detrusor inactivity with sphincter overactivity

c) Detrusor overactivity with sphincter inactivity

d) Detrusor inactivity with sphincter inactivity

Based on this simple classification of NB, the therapeutic strategy is provided for each child. The most important factors from UD investigations predicting risk of complications are as follows:

a) Increased above $40-\mathrm{cm} \mathrm{H} 2 \mathrm{O}$ detrusor leak point pressure (DLPP)

DLPP is the lowest value of detrusor pressure at which leakage is observed in the absence of abdominal strain or detrusor contraction.

b) Decreased bladder compliance, less than $20-\mathrm{mL} / \mathrm{cm} \mathrm{H} 2 \mathrm{O}$

Bladder compliance is the relationship between change in bladder volume $(\Delta \mathrm{V})$ and change in detrusor pressure. ( $\Delta$ Pdet $): \mathrm{C}=\Delta \mathrm{V} / \Delta \mathrm{Pdet}(\mathrm{mL} / \mathrm{cmH} 2 \mathrm{O})$.

\section{c) Detrusor-Sphincter-Dyssynergia (DSD)}

DSD is a detrusor contraction simultaneous with contraction of the urethra and/or periurethral striated muscle activity.

d) Elevated storage pressure with decreased bladder capacity

Both are caused by detrusor overactivity (DO). Decrease in storage pressure could be gained by correcting DO and increasing bladder compliance [3, 6, 8-15].

DO is a urodynamic observation characterized by involuntary detrusor contraction during the filling phase which may be spontaneous or provoked. The diagnosis of DO is based on the observations from UD investigations. If those contractions are caused by a neurogenic condition, we call them neurogenic DO. The neurogenic DO is most commonly seen in children 
with SD and spinal cord injury but can also be seen in patients with cerebral palsy. In the majority of cases in the literature, urinary incontinence among patients with underlying neurological conditions was found to be associated with $\mathrm{DO}[6,8,9$, 12].

\section{Treatments and Procedures}

\section{Conservative Treatment}

That treatment of a child with NB begins with the conservative methods. The two most important forms of conservative treatment of a child with NB are clean intermittent catheterization (CIC) and correction of elevated bladder pressure.

\section{Optimization of Bladder Emptying}

The aim of this treatment is the protection of urinary tract from urinary tract infections due to residual urine and protection of upper urinary tract from the development of complications due to high voiding pressure.

Clean Intermittent Catheterization Jack Lapides introduced CIC in 1972 as a method of bladder emptying in patients with NB [16]. This method is simple and effective. It can be performed beginning in the newborn period. CIC empties the bladder completely without any residual urine and by this, it is decreasing the risk of urinary tract infections and keeps the child safe of vesico-ureteric reflux due to high voiding pressure. In older children, it is a valuable tool to keep the child dry $[1,3,8,12,13]$.

a-Blockers DSD leads to ineffective voiding with significant residual urine, and it is one of the fundamental functional problems in a child with NB. The sympathetic part of the autonomic nervous system is primarily responsible for urine continence. In the sphincter and bladder neck muscles, a prevalence of $\alpha_{1}$-andregenic receptors is found. Their activation increases the sphincter mechanism tension, and their inactivation enables voiding. Since the 1970 s, $\alpha_{1}$-blockers have been used to reduce sphincter tension and to eliminate functional infravesical obstruction. Those drugs act through reversible blocking of $\alpha_{1}$-adrenergic receptors located in the muscles of the bladder neck and urethral sphincters [17, 18].

Several preparations are available in the group of $\alpha_{1^{-}}$ selective blockers, but none of those drugs have formal approval for usage in children, so treatment with any $\alpha_{1 \text { - }}$ blocker is off label. There are only few reports on the use of $\alpha_{1}$-blockers in children with NB and infravesical obstruction. Data from those studies are conflicting, showing variable degree of efficacy, so there is no evidence for this kind of treatment [19-23].

\section{Decreasing Elevated Storage Pressure}

The aim of decreasing storage pressure is the protection of urinary tract from the development of complications and improvement of continence in older children.

Antimuscarinics Antimuscarinic or anticholinergic drugs represent the golden standard of pharmacologic treatment of increased intravesical pressure. DO, involuntary contractions of the detrusor muscle are mediated by acetylcholine-induced stimulation of muscarinic receptors. Oxybutynin was introduced in the 1970s, and anticholinergic drugs are associated with a $40 \%$ increased likelihood of improvement and significantly decreased number of leakage and voiding episodes compared with placebo. Antimuscarinics have antispasmodic and local anesthetic properties that augment its effect on DO. Muscarinic M1 receptors are found also in the brain, salivary glands, and intestine sympathetic ganglia, which are responsible for most of the side effects noted during antimuscarinic therapy. Dry mouth, constipation, and elevated body temperature are the most common side effects on anticholinergic therapy. Gastroesophageal reflux, blurry vision, urinary retention, and cognitive adverse events can also occur. These symptoms are generally less frequent and less bothersome in children than in adults. Seven different antimuscarinic drugs are currently available on the market: oxybutynin, solifenacin, tolterodine, propiverine, trospium chloride, darifenacin, and fesoterodine, but not all of them have gained registration for treatment in children with NB [24-28].

$\beta_{3}$-Adrenoceptor Agonist Mirabegron is a $\beta_{3}$-adrenoceptor agonist developed for the treatment of DO. The $\beta_{3^{-}}$adrenoceptor plays an important role in the relaxation of the detrusor muscle. Mirabegron acting $\beta_{3}$-adrenoceptor relaxes the detrusor muscle during the storage phase with increasing bladder capacity. Mirabegron appears to be a safe and effective alternative for children with side effects on antimuscarinic therapy or with DO refractory to antimuscarinics, but, so far, its usage in children is off label $[29,30]$.

\section{Surgical Treatment}

The gold standard in the treatment of a child with neurogenic bladder for DO is oral therapy with anticholinergic drugs [31, $32 \bullet \bullet, 33]$. Nevertheless, in a number of children, such an approach fails to increase bladder volume and decrease detrusor pressure, low bladder capacity, and urinary incontinence persists. In some patients, troublesome side effects occur. In cases when standard therapy gives no improvement or if complications develop on the proper conservative treatment, surgical procedures are suggested. Operations are aimed at the surgical enlargement of bladder capacity. 
At present, bladder augmentation represents the most effective way of surgical improvement of bladder's function, leading to an increase in capacity and a decrease in intravesical pressure [31-35]. However, augmentation cystoplasty is a major reconstructive surgery with a significant complication rate [36]. One of the main indications for the use of BTX in children with NB is to delay or avoid the need for augmentation cystoplasty $[37,38 \bullet \bullet, 39]$. Especially in younger children, the operative vesicostomy provides an effective way to evacuate urine to decrease intravesical pressures [40, 41]. Cystoscopic administration of BTX represents an alternative method of treatment to surgery for children with NB [42].

\section{Botulinum Toxin}

Botulinum toxin (BTX) was first isolated from Clostridium botulinum bacteria by van Ermengem. Originally, seven serotypes of BTX were described, but botulinum toxin A is used most frequently in the urologic field. Two forms of BTX-A, onabotulinumtoxinA (Botox ${ }^{\circledR}$, Allergan) and abobotulinumtoxinA (Dysport $\AA$, Ibsen), have been evaluated for the treatment of NDO. The outcomes of both are comparable [37, 43].

Both the American Urologic Association (AUA) and the European Association of Urology (EAU) guidelines suggest that intravesical injection of BTX should be offered to patients with urgency urinary incontinence refractory to antimuscarinic therapy. The US Food and Drug Administration (FDA) approved BTX in 2011 for neurogenic and idiopathic detrusor overactivity. Recently, there are ongoing some trials for formal registration of Botox administration in children with NDO and IDO $[44,45]$.

The BTX molecule is composed of a $100 \mathrm{kDa}$ heavy and a $50 \mathrm{kDa}$ light chain polypeptides joined by a disulfide bond. The initial proposed mechanism of BTX action was that by attachment of the heavy chain to the receptor SV2 on axon terminals, the toxin could enter the neuron by endocytosis. The light chain cleaves synaptosomal-associated protein SNAP-25. As a result, the fusion of neurosecretory vesicles and the release of acetylcholine from pre-synaptic nerve terminals are blocked. The toxin penetrates the cell membrane and temporarily blocks the pre-synaptic release of acetylcholine from the parasympathetic efferent innervations. With the inhibition of acetylcholine release, the effect on suburothelial afferent and detrusor parasympathetic nerve endings is abolished, which was similar to the action of anticholinergic drugs [46-48].

The suggested mechanism is multidirectional and involves acting not only on the fusion protein SNAP-25, synaptic protein VAMP, but also Substance P, muscular receptors M2 and $\mathrm{M} 3$, capsaicin receptor TRPV1, purinergic receptor P2X2, $\mathrm{P} 2 \mathrm{X} 3$, urine nerve growth factor (NGF), transforming growth factor beta 1 (TGF-Beta-1), tissue inhibitor of matrix metalloproteinase 2 (TIMP-2), and other factors. The action of BTX is reversible [49-52].

In urology, BTX has been used as a cystoscopic procedure (CS) mainly to inject detrusor muscles in order to decrease intravesical pressure in the storage phase, but it has also been applied to sphincters to abolish DSD effect in the voiding phase. Most of the reports pertained to the treatment of adult patients, but some of them reported good results also in children [32••, 33-35, 37-39, 53, 54]. A systematic review of BTX treatment in children was performed by Hascoet in 2016. This study included 12 studies with 293 patients younger than 18 years of age. In this review, there was no randomized trial comparing BTX-A versus placebo and most studies had no control group. It was concluded that most studies demonstrated an improvement in both clinical symptoms and UD parameters. Complete resolution of incontinence occurred in $32-100 \%$ of patients. Two studies suggested that BTX has lower efficacy in patients with low bladder compliance. Intradetrusor injections of BTX could be effective in children with NB but this possibility is not supported by a high level of evidence [32••]. There are no reports of randomized, doubleblind, placebo controlled clinical trials on children with NB treated with BTX.

In 2005, Schurch randomized 59 patients with NB to receive a single dose of $200 \mathrm{U}$ or $300 \mathrm{U}$ BTX or placebo and concluded that intradetrusor injection of BTX was associated with a clinically significant improvement in urinary incontinence caused by DO [55]. In another randomized, doubleblind, placebo-controlled trial reported by Herschorn, patients experienced a reduction in their urinary incontinence by $50 \%$ with improvement in urodynamic parameters after BTX injection [56]. In four randomized double-blind, placebocontrolled trials on a total of 807 patients, BTX effectively improved clinical outcomes and urodynamic findings in patients with neurogenic DO [57].

\section{Cystoscopic Procedure}

According to the literature, while many children undergo CS under general anesthesia, it has been reported that CS could be performed without any anesthesia, as the majority of children with NB and MMC have no sensation of the lower urinary tract. During CS, a rigid or flexible cystoscope with an operative channel is used. The diameter of the instrument should be adjusted to the age of a patient and the size of the urethra. The bladder is filled with the solution. A rigid needle is introduced through the operative channel of a cystoscope. The dose of BTX is calculated for every patient according to the age and the body mass, and diluted in 10-20 $\mathrm{ml} 0.9 \% \mathrm{NaCl}$. The dose of the toxin is administered in divided portions into the bladder dome. In the majority of studies, 20-30 consecutive sites of bladder dome were injected each with a small 
portion of the solution $[32 \bullet \bullet, 33-35,37,38 \bullet \bullet, 39,53-57,58 \bullet]$. Some authors postulated only ten injection sites are necessary while others concluded that up to 50 consecutive injections are needed [37, 59].

The injection is performed into the detrusor muscle while some authors suggested to inject it superficially: suburothelial/ submucosal $[60 \bullet, 61]$. Some urologists postulated not to inject the preparation into regions of ureteric orifices sparing the trigone $[59,62,63]$. Others advised to inject the BTX preparation also into the bladder trigone $[64,65 \cdot, 66]$. Following the procedure, urine is evacuated from the bladder by catheterization.

In a study from 2018 intravesical electromotive method of BTX (Dysport), administration in patients with NDO was investigated. The results of this study have shown that this method is a feasible, safe, reproducible, cost-effective, long-lasting, and pain-free method on an outpatient basis without anesthesia or cystoscopy procedure. This delivery system resulted in considerable improvement in urinary incontinence and urodynamic study parameters in patients with refractory NDO [67].

\section{Effects of BTX Detrusor Injection}

The expected effect of BTX detrusor injection should be increased in bladder capacity and decrease in intravesical pressure. The outcomes of BTX injections are assessed both in VD and UD investigations. UD examinations are essential for the assessment of the functioning of the lower urinary tract and are recommended as a routine part of the follow-up in children after BTX injection [68••].

In the literature, some parameters from cystometric evaluation were measured and compared. First, most authors noted an increase in maximal cystometric capacity (MCC) with a decrease of maximum detrusor pressure (MDP) [37]. In a study by Neel, MCC increased significantly from 96 to $163 \mathrm{ml}$, and the MDP decreased significantly from 76 to $50 \mathrm{~cm} \mathrm{H} 2 \mathrm{O}$ [69]. Schulte-Baukloh reported MCC change from 163.1 to $219.9 \mathrm{ml}$, MDP changed from 59.6 to $34.9 \mathrm{~cm} \mathrm{H2O} \mathrm{[35].} \mathrm{Efficacy} \mathrm{of} \mathrm{BTX} \mathrm{injections} \mathrm{in} \mathrm{the} \mathrm{detrusor}$ and an increase in MCC with a decrease of MDP has been noted by other authors in 32 to $100 \%$ of patients [32••, 33-35, 37-39, 53-57, 58•]. In some papers, detrusor reflex volume (DRV), volume at which the first detrusor contraction occurred, was measured [37, 39]. According to SchulteBaukloh, in the follow-up cystometry, mean reflex volume changed from $97.1 \mathrm{ml}$ before injection to $178.6 \mathrm{ml}$ after 4 weeks [35].

It is still disputable if intradetrusor injections of BTX will affect the tension of sphincters reflected by a change in DLPP and bladder walls compliance. In some studies, positive changes in DLPP were observed after BTX injection in detrusor muscle. In a study from 2012 , leak point pressure decreased from 46.5 to $24.2 \mathrm{~cm} \mathrm{H2O} \mathrm{[58•].} \mathrm{The} 66 \%$ clinical success rate described by Hascoet was significantly associated with a decrease in maximum urethral closure pressure $(34 \mathrm{~cm}$ $\mathrm{H} 2 \mathrm{O}$ vs $54.4 \mathrm{~cm} \mathrm{H2O}$ ) [2]. In a randomized trial of 60 patients with NB: in one group, $10 \mathrm{IU} / \mathrm{kg}$ of BTX was injected into the detrusor muscle; in the second group: $8 \mathrm{IU} / \mathrm{kg}$ into detrusor and $2 \mathrm{IU} / \mathrm{kg}$ in external urethral sphincter. It was found that additional BTX injections in sphincter have extra benefits such as decreasing postvoiding residual volume and more symptom diminution compared with intradetrusal injections alone [34].

BTX injection has shown effectiveness in the treatment of detrusor sphincter dyssynergia when injected into sphincters either transurethral or transperineally. After treatment, external urethral sphincter pressure, voiding pressure, and post-void residual volume demonstrate a decrease. The effect is reported to last between 2 and 12 months. [70] In a study of Mokhless, endoscopic injection of a dose of 100 IU of Botox into the hypertrophied bladder neck does not improve the outcome of boys with voiding dysfunction after valve ablation [71].

Bladder compliance improvement was observed by some

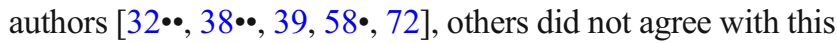
observation $[33,34,73]$. Botulinum toxin $\mathrm{A}$ injection in the NB was found to be ineffective if the detrusor was fibrotic, of low compliance, and had lost contractility [74]. Even poor bladder compliance was described as predictor of poor response after BTX-A injection [75].

\section{Continence}

The increase in bladder capacity should be reflected in the improvement in continence status. This was measured in different scales by some authors. In a study of SchulteBaukloh, there was 33\% reduction in the score at week 2 4 after the cystoscopic procedure [35]. According to Khan, $75 \%$ of patients were continent between CIC [33]. Similar improvements (73\%) were noted by Kajbafzadeh, and the total improvement in urine incontinence was $88 \%$ [46]. Figueroa reported the $76.9 \%$ improvement in continence was followed by $70.6 \%$ overall patient/parental reported satisfaction rate [77]. In a recent, multicenter study, clinical improvement was noted in $66 \%$ of patients [32••]. In a group of children described by Khan, overall $54 \%$ of children had improved continence after the initial BTX injection, whereas $45 \%$ had achieved complete continence between catheterizations [3]. In a study from 2007, from a clinical point of view, 9 of the 16 incontinent patients (56.2\%) showed complete continence after treatment while $4(25 \%)$ reported mild to moderate improvement and $3(18.8 \%)$ showed no improvement [79]. In other studies, 50 to $100 \%$ of patients were dry at 3-6 months after the BTX injection. [34, 37, 59, 72, 78] 


\section{Dosage}

Only onabotulinum, Botox (Allergan) has registration for treatment DO, but there are some studies on abobotulinum, Dysport (Ibsen) treatment of DO in urology. Those two preparations are not equivalent both in the duration of action and effective dosage. Taken together, the findings retrieved from the literature suggest a conversion ratio of $1: 3$ or 1:4 for Botox and Dysport. In NBO in adults, a dosage of BTX has been reported at 500 to 1500 units of abobotulinum or 100 to 300 units of onabotulinum. In children, respectively $10-30 \mathrm{U} / \mathrm{kg}$ body weight abobotulinum or $2.5-12 \mathrm{U} / \mathrm{kg}$ body weight of onabotulinum were used [37, 43-45, 54, 57, 79]. The most commonly used dose of onabotulinum toxin in these patients is $10-12 \mathrm{U} / \mathrm{kg}$ with a maximal dose of $300 \mathrm{U}[5,7,24,27-29]$. In a study of Altaweel, the bladder was injected with $5 \mathrm{U} / \mathrm{kg}$ body weight with a maximum dosage of 300 IU for patient. Safari used 8 or $10 \mathrm{U} / \mathrm{kg}$, Riccabona and Kajbafzadeh $10 \mathrm{U} /$ kg, Do Ngoc Thanh 6-11 U/kg, and Schulte-Baukloh 12 U/kg to a maximum of $360 \mathrm{U}$ per patient $[35,39,59,62,63,76,78]$.

Estimating the optimal dosage of BTX preparations both in children and adults is still under investigation. Some papers showed, both for Botox or Dysport, no clear dose-related effect with the observation indicating that a dose greater than $50 \mathrm{U}$ is significantly more effective for certain symptoms of OAB compared with placebo [37]. One dose ranging study on rats with Dysport and Botox under standardized conditions showed similar inhibiting effects on NDO [43].

\section{Persistence of Effect}

The activity of BTX in the urinary bladder was described to persist for 6-9 months and with reports as long as 12 months. Afterwards, the procedure can be repeated. In a study of Herschorn, improved urodynamic parameters for treatment vs placebo persisted to weeks 24 to 36 [56]. In a group of 28 children described by Zeino, the efficacy of BTX injection lasted a mean of 12 months and the urodynamic response was unchanged even after several injections [58•]. Also in the observations of Horst, 12 months after treatment, patients still had an effect [73]. According to Riccabona, mean durability of the effect of the drug was 10.5 months after the first as well as after the second intravesical injection [59]. In a study of Kask, median duration of the response after BTX injection was 15 months (range 3-42 months) [34].

Only one controlled study reported the effects of different dosages of BTX for treatment patients with DO at 36 weeks [80].

\section{Repeated Injections}

In many observations, repeated intradetrusor BTX injections were found to be equally effective as the first application. In some studies, the procedure was repeated more than ten times with the same effect as the first injection [37, 38••, 39, 47, 57, $58 \bullet, 65 \bullet, 72]$. In some studies, Botox remained effective after up to 11 injections [81].

\section{Influence on Upper Urinary Tract}

Improvement in bladder function can lead to resolution of vesicoureteral reflux. In a study by Kajbafzadeh et al. of 15 patients with varying degrees of vesicoureteral reflux before the procedure, $11(73 \%)$ had a decrease in the reflux grade [76]. Simultaneous BTX injection in detrusor and sphincters showed better outcomes in relation to the resolution of vesicoureteral reflux than intra detrusor BTX injection alone [63]. Further improvement in the treatment of children with complications of NB is the total endoscopic management which is a combination of intradetrusor BTX injection along with endoscopic treatment of vesicoureteral reflux. Fifteen out of $16(93.75 \%)$ refluxing ureters were completely resolved by this kind of treatment [82•]. BTX treatment may confer longterm bladder and upper tract protection in the neurogenic patient group, treating new-onset hydronephrosis secondary to the neurogenic bladder [81]. Furthermore, BTX treatment was found to be a cost-effective therapy for $\mathrm{OB}$ and should be further explored as a first line option in the treatment paradigm $[83 \bullet \bullet$.

\section{Side Effects}

According to the data from many studies, serious adverse events (SAE) related to the procedure of BTX injection have

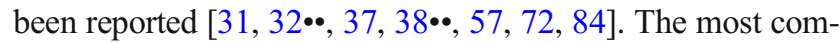
mon adverse event after BTX injection was urinary tract infection. Elevated post-void residual were seen in patients voiding spontaneously. In a study of Greer, three children $(2.8 \%)$ developed urinary retention after intravesical BTX injection [81]. In another study, post procedure urinary retention requiring catheterization was only $1.6 \%$ [85]. In reports from other studies, none of the patients had side effects related to the procedure or the material used. But caution must be taken when BTX-A is used in patients under age 18 years of age. BTX is specified as pregnancy category $\mathrm{C}$, where there are no adequate and well-controlled studies in children and it should only be used if the potential benefits justify the potential risk to the fetus $[33,56,69,86,87]$.

\section{Follow-up Recommendations for Children Following BTX Injection}

Currently, there are no available guidelines for follow up after intravesical BTX injection. Due to the risk of developing complications also in children under proper conservative treatment, patients with NB need periodic urology check-ups and 
repeated diagnostic tests. Further regular follow-up visits at the urology office are mandatory. The evaluation of the bladder function in children starts with completing VD. Urinalysis should be performed monthly and urine culture only in the case of symptomatic urinary tract infections. Abdominal US and UD testing to be performed every 6-12 months according to risk factors. Video-UD or cystography and renal scans should be performed immediately in case of confirmed change in urinary tract function, continence status, or deterioration in urinary tract confirmed in US $[3,7,8,56,58 \bullet]$.

\section{Conclusions}

Endoscopic administration of the BTX should be considered an alternative method of treatment of children with NB in the following cases: lack of efficacy on oral conservative treatment, side effects of anticholinergic drugs, and lack of parental consent to surgical treatment (vesicostomy or surgical bladder augmentation). This kind of treatment could be also considered an alternative to oral anticholinergic therapy.

\section{Compliance with Ethical Standards}

Conflict of Interest The author declares that he has no conflicts of interest.

Human and Animal Rights and Informed Consent This article does not contain any studies with human or animal subjects performed by any of the authors.

Open Access This article is distributed under the terms of the Creative Commons Attribution 4.0 International License (http:// creativecommons.org/licenses/by/4.0/), which permits unrestricted use, distribution, and reproduction in any medium, provided you give appropriate credit to the original author(s) and the source, provide a link to the Creative Commons license, and indicate if changes were made.

\section{References}

Papers of particular interest, published recently, have been highlighted as:

- Of importance

-• Of major importance

1. Rackley R, Vasavada SP, Firoozi F, Ingber MS 2009 Neurogenic bladder. eMedicine. Available at: http://emedicine.medscape.com/ article/453539-overview\#showall. Accessed 09 Jan 2019.

2. Fowler CJ, Griffiths D, de Groat WC. The neural control of micturition. Nat Rev Neurosci. 2008;9:453-66.

3. Kroll P, Zachwieja J. Complications of untreated and ineffectively treated neurogenic bladder dysfunctions in children: our own practical classification. Eur Rev Med Pharmacol Sci. 2016;20:1229-37.

4. Marshall DF, Boston VE. Does bladder capacity assessment by frequency/volume chart correlate well with urodynamic estimation in children with spina bifida? Eur J Pediatr Surg. 2001;11(Suppl 1): S24-7.

5. Hjälmås K. Urodynamics in normal infants and children. Scand J Urol Nephrol Suppl. 1988;114:20-7.

6. Austin PF, Bauer SB, Bower W, Chase J, Franco I, Hoebeke P, et al. The standardization of terminology of lower urinary tract function in children and adolescents: update report from the Standardization Committee of the International Children's Continence Society. Neurourol Urodynam. 2016;35:471-81.

7. Madersbacher $\mathrm{H}$. The various types of neurogenic bladder dysfunction: an update of current therapeutic concepts. Paraplegia. 1990;28:217-29.

8. Snow-Lisy DC, Yerkes EB, Cheng EY. Update on urological management of spina bifida from prenatal diagnosis to adulthood. J Urol. 2015;194:288-96.

9. Pannek J., Blok B., Castro-Diaz D., Del Popolo G., Kramer G., Radziszewski $p$ et al. EAU Guidelines on Neurogenic Lower Urinary Tract Dysfunction https://uroweb.org/wp-content/.../20 Neurogenic-LUTD_LR. Accessed 09 Jan 2019.

10. McGuire EJ, Woodside JR, Bordin TA, Weiss RM. Prognostic value of urodynamic testing in myelodysplastic patients. J Urol. 1981;136:205-9.

11. Bauer SB, Hallet M, Khoshbin S, Lebowitz RL, Winston KR, Gibson S, et al. Predective value of urodynamic evaluation in newborns with myelodysplasia. JAMA. 1984;252:650-65.

12. Stein R, Assion C, Beetz R, Bürst M, Cremer R, Ermert A, et al. Neurogene Blasenfunktions-störungen bei Patienten mit Meningomyelozele. Urologe A. 2015;54:239-53.

13. Gerridzen RG, Thijssen AM, Dehoux E. Risk factors for upper tract deterioration in chronic spinal cord injury patients. J Urol. 1992;147:416-8.

14. Mourtzinos A, Stoffel JT. Management goals for the spina bifida neurogenic bladder: a review from infancy to adulthood. Urol Clin North Am. 2010;37:527-35.

15. Baek M, Kang JY, Jeong J, Kim DK, Kim KM. Treatment outcomes according to neuropathic bladder sphincter dysfunction type after treatment of oxybutynin chloride in children with myelodysplasia. Int Urol Nephrol. 2013;45:703-9.

16. Lapides J, Diokno AC, Silber SJ, Lowe BS. Clean intermittent selfcatheterization in the treatment of urinary tract disease. J Urol. 1972;107:458-61.

17. Krane RJ, Olsson CA. Phenoxybenzamine in neurogenic bladder dysfunction. I. A theory of micturition. J Urol. 1973;110:650-2.

18. Yamanishi T, Yasuda K, Sakakibara R, Hattori T, Tojo M. The effectiveness of terazosin, an alpha1-blocker, on bladder neck obstruction as assessed by urodynamic hydraulic energy. BJU Int. 2000;85:249-53.

19. de Voogt HJ, van der Sluis C. Preliminary evaluation of alphaadrenergic blocking agents in children with neurogenic bladder due to myelomeningocele. Dev Med Child Neurol Suppl. 1976;37:82-8.

20. Schulte-Baukloh H, Michael T, Miller K, Knispel HH. Alfuzosin in the treatment of high leak-point pressure in children with neurogenic bladder. BJU Int. 2002;90:716-20.

21. Homsy Y, Arnold P, Zhang W. Phase IIb/III dose ranging study of tamsulosin as treatment for children with neuropathic bladder. J Urol. 2011;186:2033-9.

22. Kroll P, Gajewska E, Zachwieja J, Sobieska M, Makowski P. An evaluation of the efficacy of selective alpha-blockers in the treatment of children with neurogenic bladder dysfunction-preliminary findings. Int J Environ Res Public Health. 2016;15,13(3)

23. Austin PF, Homsy YL, Masel JL, Cain MP, Casale AJ, Rink RC. Alpha-adrenergic blockade in children with neuropathic and nonneuropathic voiding dysfunction. J Urol. 1999;162:1064-7.

24. Finney SM, Andersson KE, Gillespie JI, Stewart LH. Antimuscarinic drugs in detrusor overactivity and the overactive 
bladder syndrome: motor or sensory actions? BJU Int. 2006;98: 503-7.

25. Blais AS, Bergeron M, Nadeau G, Ramsay S, Bolduc S. Anticholinergic use in children: persistence and patterns of therapy. Can Urol Assoc J. 2016;10:137-40.

26. Park SJ, Pai KS, Kim JM, Park K, Kim KS, Song SH, et al. Korean children's continence and enuresis society. Efficacy and tolerability of anticholinergics in Korean children with overactive bladder: a multicenter retrospective study. J Korean Med Sci. 2014;29:1550 4.

27. Nabi G, Cody JD, Ellis G, Herbison P, Hay-Smith J. Anticholinergic drugs versus placebo for overactive bladder syndrome in adults. Cochrane Database Syst Rev. 2006;4:CD003781.

28. Bolduc S, Moore K, Nadeau G, Lebel S, Lamontage P, Hamel M. Prospective open label study of solifenacin for overactive bladder in children. J Urol. 2010;184:1668-73.

29. Blais AS, Nadeau G, Moore K, Genois L, Bolduc S. Prospective pilot study of Mirabegron in pediatric patients with overactive bladder. Eur Urol. 2016;70:9-13.

30. Morin F, Blais AS, Nadeau G, Moore K, Genois L, Bolduc S. Dual therapy for refractory overactive bladder in children: a prospective open-label study. J Urol. 2016 Nov 30

31. Lee B, Featherstone N, Nagappan P, McCarthy L, O'Toole S. British Association of Paediatric Urologists consensus statement on the management of the neuropathic bladder. J Pediatr Urol. 2016;12:76-87.

32.• Hascoet J, Peyronnet B, Forin V, Baron M, Capon G, Prudhomme T, et al. Intradetrusor injections of botulinum toxin type a in children with spina bifida: a multicenter study. Urology. 2018;116:161-7. A multicenter trial on 53 children in mean age of 8.5 years showed clinical improvement in $66 \%$ patients.

33. Khan MK, VanderBrink B A, DeFoor WR, Minevich E, Jackson E, Noh $\mathrm{P}$ et al. Botulinum toxin injection in the pediatric population with medically refractory neuropathic bladder. J Pediatr Urol. 2016; 12: 104.e1-6.

34. Kask M, Rintala R, Taskinen S. Effect of onabotulinumtoxinA treatment on symptoms and urodynamic findings in pediatric neurogenic bladder. J Pediatr Urol. 2014;10:280-3.

35. Schulte-Baukloh H, Michael T, Stürzebecher B, Knispel HH. Botulinum-a toxin detrusor injection as a novel approach in the treatment of bladder spasticity in children with neurogenic bladder. Eur Urol. 2003;44:139-43.

36. Krebs J, Bartel P, Pannek J. Functional outcome of supratrigonal cystectomy and augmentation ileocystoplasty in adult patients with refractory neurogenic lower urinary tract dysfunction. Neurourol Urodyn. 2016;35:260-6.

37. Gu HY, Song JK, Zhang WJ, Xie J, Yao QS, Zeng WJ, et al. A systematic review and meta-analysis of effectiveness and safety of therapy for overactive bladder using botulinum toxin A at different dosages. Oncotarget. 2017;8:90338-50.

38.• Sekerci CA, Tanidir Y, Garayev A, Akbal C, Tarcan T, Simsek F. Clinical and urodynamic results of repeated intradetrusor onabotulinum toxin A injections in refractory neurogenic detrusor overactivity: up to 5 injections in a cohort of children with myelodysplasia. Urology. 2018;111:168-75. A study showing that repeated injections of BTX-A are a safe and effective treatment modality in children with $\mathrm{NB}$.

39. Do Ngoc Thanh C, Audry G, Forin V. Botulinum toxin type A for neurogenic detrusor overactivity due to spinal cord lesions in children: a retrospective study of seven cases. J Pediatr Urol. 2009;5: 430-6.

40. Hendren WH. Some alternatives to urinary diversion in children. J Urol. 1978;119:652-60.

41. Morrisroe SN, O'Connor RC, Nanigian DK, Kurzrock EA, Stone AR. Vesicostomy revisited: the best treatment for the hostile bladder in myelodysplastic children? BJU. 2005;97:397-400.
42. González R, Ludwikowski BM. Alternatives to conventional enterocystoplasty in children: a critical review of urodynamic outcomes. Front Pediatr. 2013;1:1-9.

43. Behr-Roussel D, Oger S, Pignol B, Pham E, Le Maux A, Chabrier PE et.al: Minimal effective dose of dysport and botox in a rat model of neurogenic detrusor overactivity. Eur Urol 2012; 61: 1054-1061.

44. Gormley EA, Lightner DJ, Faraday M, Vasavada SP. American urological association; Society of Urodynamics, female pelvic medicine. Diagnosis and treatment of overactive bladder (nonneurogenic) in adults: AUA/SUFU guideline amendment. J Urol. 2015;193:1572-80.

45. Lucas MG, Bosch RJ, Burkhard FC, Cruz F, Madden TB, Nambiar AK, et al. European Association of Urology. EAU guidelines on surgical treatment of urinary incontinence. Eur Urol. 2012;62: 1118-29.

46. Dolly JO, Lawrence GW. Chapter 3: molecular basis for the therapeutic effectiveness of botulinum neurotoxin type a. Neurourol Urodyn. 2014;33:14-20.

47. Li B, Peet NP, Butler MM, Burnett JC, Moir DT, Bowlin TL. Small molecule inhibitors as countermeasures for botulinum neurotoxin intoxication. Molecules. 2010;16:202-20.

48. Dong M, Yeh F, Tepp WH, Dean C, Johnson EA, Janz R, et al. SV2 is the protein receptor for botulinum neurotoxin a. Science. 2006;28:592-6.

49. Brady C, Apostolidis A, Yiangou Y, Baecker PA, Ford AP, Freeman A, et al. P2X3-immunoreactive nerve fibres in neurogenic detrusor overactivity and the effect of intravesical resiniferatoxin (RTX). Eur Urol. 2004;46:247-53.

50. Apostolidis A, Popat R, Yiangou Y, Cockayne D, Ford AP, Davis $\mathrm{JB}$, et al. Decreased sensory receptors P2X3 and TRPV1 in suburothelial nerve fibers following intradetrusor injections of botulinum toxin for human detrusor overactivity. J Urol. 2005;174: 977-83.

51. Top T, Sekerci CA, Isbilen-Basok B, Tanidir Y, Tinay I, Isman FK, et al. The effect of intradetrusor botulinum neurotoxin type A on urinary NGF, TGF BETA-1, TIMP-2 levels in children with neurogenic detrusor overactivity due to myelodysplasia. Neurourol Urodyn. 2017;36:1896-902.

52. Schulte-Baukloh H, Priefert J, Knispel HH, Lawrence GW, Miller K, Neuhaus J. Botulinum toxin A detrusor injections reduce postsynaptic muscular M2, M3, P2X2, and P2X3 receptors in children and adolescents who have neurogenic detrusor overactivity: a single-blind study. Urology. 2013 May;81(5):1052-7.

53. Hassouna T, Gleason JM, Lorenzo AJ. Botulinum toxin A's expanding role in the management of pediatric lower urinary tract dysfunction. Curr Urol Rep. 2014;15:426.

54. Gamé X, Mouracade P, Chartier-Kastler E, Viehweger E, Moog R, Amarenco G, et al. Botulinum toxin-A (Botox) intradetrusor injections in children with neurogenic detrusor overactivity/neurogenic overactive bladder: a systematic literature review. J Pediatr Urol. 2009;5(3):156-64.

55. Schurch B, de Sèze M, Denys P, Chartier-Kastler E, Haab F, Everaert K, et al. Botulinum toxin type a is a safe and effective treatment for neurogenic urinary incontinence: results of a single treatment, randomized, placebo controlled 6-month study. J Urol. 2005;174:196-200.

56. Herschorn S, Gajewski J, Ethans K, Corcos J, Carlson K, Bailly G, et al. Efficacy of botulinum toxin A injection for neurogenic detrusor overactivity and urinary incontinence: a randomized, double-blind trial. J Urol. 2011;185:2229-35.

57. Zhou X, Yan HL, Cui YS, Zong HT, Zhang Y: Efficacy and safety of onabotulinumtoxinA in treating neurogenic detrusor overactivity: a systematic review and meta-analysis. Chin Med J (Engl). 2015; 128: 963-8.

58. Zeino M, Becker T, Koen M, Berger C. Riccabona M: Long-term follow-up after botulinum toxin A (BTX-A) injection into the 
detrusor for treatment of neurogenic detrusor hyperactivity in children. Cent European. J Urol. 2012;65:156-61. This trial showed that BTX injections were efficient even after several injections.

59. Riccabona M, Koen M, Schindler M, Goedele B, Pycha A, Lusuardi L, et al. Botulinum-A toxin injection into the detrusor: a safe alternative in the treatment of children with myelomeningocele with detrusor hyperreflexia. J Urol. 2004;171:845-8. discussion 848.

60. Šámal V, Mečl J, Šrám J. Submucosal administration of onabotulinumtoxinA in the treatment of neurogenic detrusor overactivity: pilot single-centre experience and comparison with standard injection into the detrusor. Urol Int. 2013;91:423-8. This trial did not show any significant difference between BTX administration to the submucosa and to the detrusor.

61. Krhut J, Samal V, Nemec D, Zvara P. Intradetrusor versus suburothelial onabotulinumtoxinA injections for neurogenic detrusor overactivity: a pilot study. Spinal Cord. 2012;50:904-7.

62. Marte A, Onabotulinumtoxin A. For treating overactive/poor compliant bladders in children and adolescents with neurogenic bladder secondary to myelomeningocele. Toxins (Basel). 2012;28(5):1624.

63. Safari S, Jamali S, Habibollahi P, Arshadi H, Nejat F, Kajbafzadeh AM. Intravesical injections of botulinum toxin type A for management of neuropathic bladder: a comparison of two methods. Urology. 2010 Jul;76:225-30.

64. Kuo HC. Bladder base/trigone injection is safe and as effective as bladder body injection of onabotulinumtoxinA for idiopathic detrusor overactivity refractory to antimuscarinics. Neurourol Urodyn. 2011;30:1242-8.

65. Davis NF, Burke JP, Redmond EJ, Elamin S, Brady CM, Flood HD. Trigonal versus extratrigonal botulinum toxin-A: a systematic review and meta-analysis of efficacy and adverse events. Int Urogynecol J. 2015;26:313-9. In this study no significant differences were found between trigonal and extratrigonal BTX injections.

66. Abdel-Meguid TA. Botulinum toxin-A injections into neurogenic overactive bladder-to include or exclude the trigone? A prospective, randomized, controlled trial. J Urol. 2010;184(6):2423-8.

67. Ladi-Seyedian SS, Sharifi-Rad L, Kajbafzadeh AM. Intravesical electromotive botulinum toxin type "A" administration for management of urinary incontinence secondary to neuropathic detrusor overactivity in children: long-term follow-up. Urology. 2018;114: 167-74.

68.• Koschorke M, Leitner L, Sadri H, Knüpfer SC, Mehnert U, Kessler TM. Intradetrusor onabotulinumtoxinA injections for refractory neurogenic detrusor overactivity incontinence: do we need urodynamic investigation for outcome assessment? BJU Int. 2017; 120: 848-54. This study recommend urodynamic investigations as a routine part of the follow-up in patients after BTX injestions.

69. Neel KF, Soliman S, Salem M, Seida M, Al-Hazmi H, Khatab A. Botulinum-A toxin: solo treatment for neuropathic noncompliant bladder. J Urol. 2007;178:2593-7. discussion 2597-8.

70. Tsai SJ, Ying TH, Huang YH, Cheng JW, Bih LI, Lew HL. Transperineal injection of botulinum toxin A for treatment of detrusor sphincter dyssynergia: localization with combined fluoroscopic and electromyographic guidance. Arch Phys Med Rehabil. 2009;90:832-6.

71. Mokhless I, Zahran AR, Saad A, Yehia M, Youssif ME. Effect of botox injection at the bladder neck in boys with bladder dysfunction after valve ablation. J Pediatr Urol. 2014;10:899-904.

72. Sager C, Burek C, Bortagaray J, Corbetta JP, Weller S, Durán V, et al. Repeated injections of intradetrusor onabotulinumtoxin A as adjunctive treatment of children with neurogenic bladder. Pediatr Surg Int. 2014;30:79-85.
73. Horst M, Weber DM, Bodmer C, Gobet R. Repeated botulinum-a toxin injection in the treatment of neuropathic bladder dysfunction and poor bladder compliance in children with myelomeningocele. Neurourol Urodyn. 2011;30:1546-9.

74. Tiryaki S, Yagmur I, Parlar Y, Ozel K, Akyildiz C, Avanoglu A, et al. Botulinum injection is useless on fibrotic neuropathic bladders. J Pediatr Urol. 2015;11:27.e1-4.

75. Kim SW, Choi JH, Lee YS, Han SW, Im YJ. Preoperative urodynamic factors predicting outcome of botulinum toxin-A intradetrusor injection in children with neurogenic detrusor overactivity. Urology. 2014;84:1480-4.

76. Kajbafzadeh AM, Moosavi S, Tajik P, Arshadi H, Payabvash S, Salmasi AH, et al. Intravesical injection of botulinum toxin type A: management of neuropathic bladder and bowel dysfunction in children with myelomeningocele. Urology. 2006;68:1091-6. discussion 1096-7.

77. Figueroa V, Romao R, Pippi Salle JL, Koyle MA, Braga LH, Bägli DJ, et al. Single-center experience with botulinum toxin endoscopic detrusor injection for the treatment of congenital neuropathic bladder in children: effect of dose adjustment, multiple injections, and avoidance of reconstructive procedures. J Pediatr Urol. 2014;10: 368-73.

78. Altaweel W, Jednack R, Bilodeau C, Corcos J. Repeated intradetrusor botulinum toxin type a in children with neurogenic bladder due to myelomeningocele. J Urol. 2006;175:1102-5.

79. Blackburn SC, Jones C, Bedoya S, Steinbrecher HA, Malone PS, Griffin SJ. Intravesical botulinum type-A toxin (Dysport ${ }^{\circledR}$ ) in the treatment of idiopathic detrusor overactivity in children. J Pediatr Urol. 2013;9:750-3.

80. Rovner E, Kennelly M, Schulte-Baukloh H, Zhou J, HaagMolkenteller C, Dasgupta P. Urodynamic results and clinical outcomes with intradetrusor injections of onabotulinumtoxinA in a randomized, placebo-controlled dose-finding study in idiopathic overactive bladder. Neurourol Urodyn. 2011;30:556-62.

81. Greer T, Abbott J, Breytenbach W, McGuane D, Barker A, Khosa J, et al. Ten years of experience with intravesical and intrasphincteric onabotulinumtoxinA in children. J Pediatr Urol. 2016;12:94.e1-6.

82. Neel KF, Salem M, Soliman S. Total endoscopic management (TEM approach) of children with non-compliant neuropathic bladder: a preliminary report. J Pediatr Urol. 2008;4:124-6. This trial confirmed that combination of endoscopic BTX injection with correction of vesico-ureteric reflux is a simple and effective way manage children with NB.

83.・ Shepherd JP, Carter-Brooks CM, Chermanksy C. A costeffectiveness analysis of Onabotulinumtoxin A as first-line treatment for overactivebladder. Int Urogynecol J. 2018;29:1213-9. This study showed that BTX injestion is a cost-effective therapy for overactive bladder.

84. Nuanthaisong U, Abraham N, Goldman HB. Incidence of adverse events after high doses of onabotulinumtoxinA for multiple indications. Urology. 2014;84:1044-8.

85. Patel DN, Jamnagerwalla J, Houman J, Anger JT, Eilber KS. What is the true catheterization rate after intravesical onabotulinumtoxinA injection? Int Urogynecol J. 2018;29:1005-9.

86. Bayrak O, Sadioglu E, Sen H, Dogan K, Erturhan S, Seckiner I. Efficacy of onabotulinum toxin A injection in pediatric patients with non-neurogenic detrusor overactivity. Neurourol Urodyn. 2017;36:2078-82.

87. Rovner E, Dmochowski R, Chapple C, Thompson C, Lam W, Haag-Molkenteller C. OnabotulinumtoxinA improves urodynamic outcomes in patients with neurogenic detrusor overactivity. Neurourol Urodyn. 2013;32:1109-15.

Publisher's Note Springer Nature remains neutral with regard to jurisdictional claims in published maps and institutional affiliations. 